\title{
The Zombie as a Mirror of Modern Mass Culture
}

\section{Serguey N. Yakushenkov ${ }^{1}$ \& Olesya S. Yakushenkova ${ }^{2}$}

Astrakhan State University. Astrakhan, Russia

\begin{abstract}
Zombies were and still are one of the most important symbols of modern mass culture. The zombie discourse originated among African slaves brought to the sugar plantations in the Caribbean. In many ways, the narratives of the "living dead" were a reaction to the crisis phenomena of plantation life. This is evidenced by the rich comparative material presented on many peoples of the world. Such notions of invulnerability after formal death proved to be an important tool of resistance to new conditions caused by external threats. Termed "revitalization," they were an important element of the Millennialist movements. While initially the sorcerers who could bring themselves back to life were central to these beliefs, in the following period the focus shifted to the victims of various manipulations, transformed into soulless beings. Leaving the environment of their original "habitat," zombies took on a new life, occupying a firm place in modern mass culture. Having become a symbol of ruthless exploitation of man, relegated to the level of a machine appendage, zombies proved to be one of the most "productive" symbols. They reflected the main trends in the development of society and even began to function as instruments of philosophical reflection. All this allows us to consider zombies as an indicator of altered society, producing new "walking dead". The metaphors associated with zombies allows us to conclude that the comprehension of zombies makes modern man begin to perceive them constructively, creating a new image, demonstrating the movement towards humanization.
\end{abstract}

Keywords

Zombie; Revitalization; Metaphors; Crisis Phenomena; Cultural Trends; Fears

(c) (i)

This work is licensed under a Creative Commons «Attribution» 4.0 International License

1 Email: shuilong[at]mail.ru

2 Email: zenthaya[at]gmail.com 


\title{
Зомби как зеркало современной массовой культуры
}

\section{Якушенков Сергей Николаевич ${ }^{1}$, Якушенкова Олеся Сергеевна ${ }^{2}$}

Астраханский государственный университет. Астрахань, Россия

\begin{abstract}
Аннотация
Зомби были и остаются одним из важнейших символов современной массовой культуры. Дискурс о зомби зародились в среде африканских рабов, привезенных на сахарные плантации на Карибах. Во многом нарративы об «оживающих мертвецах» явились реакцией на кризисные явления плантационной жизни. Об этом свидетельствует богатый сравнительный материал, представленный по многим народам мира. Подобные представления о неуязвимости после формальной смерти оказались важным инструментом сопротивления новым условиям, вызванным внешней угрозой. Названные «ревитализацией», они явились важным элементом милленаристских движений. Если изначально центральное место в этих воззрениях играли колдуны, способные возвращать себя к жизни, то в последующий период основное внимание сместилось на жертв различных манипуляций, превращающих людей в бездушные существа. Покинув среду первоначального «обитания», зомби зажили новой жизнью, заняв прочное место в современной массовой культуре. Став символом нещадной эксплуатации человека, низведенного до уровня придатка машины, зомби оказались одним из наиболее «продуктивных» символов. Они отразили основные тенденции развития общества и даже начали функционировать как инструмент философского осмысления. Все это позволяет рассматривать зомби как индикатор алертности общества, продуцирующего новых «ходячих мертвецов». Многообразие метафор, связанных с зомби, позволяет сделать вывод о том, что осмысление зомби заставляет современного человека начать воспринимать его не с позиции полного отрицания, а конструктивно, создав новый образ, демонстрирующий движение к гуманизации.
\end{abstract}

\section{Ключевые слова}

зомби; ревитализация; метафоры; кризисные явления; культурные тенденции; страхи

Это произведение доступно по лицензии Creative Commons «Attribution» («Атрибуция») 4.0 Всемирная

1 Email: shuilong[at]mail.ru

2 Email: zenthaya[at]gmail.com 


\section{Введение}

Сразу признаемся, что мы выбрали данное название не потому, что считаем зомби зеркалом современной массовой культуры (хотя это отчасти именно так). Важной была отсылка к работе В.Ленина (Ленин, 1958, pp. 179-186), название которой стало своеобразным штампом (Быков, 2021). Известный журналист и писатель Дмитрий Быков употребил это название по отношению к сразу нескольким персонажам, сократив их фамилии до аббревиатуры. Это предоставило ему широкий маневр для действия, предоставив читателю возможность самому делать выводы об объекте повествования. В такой стратегии нет ничего удивительного, так как зеркало отражает сразу множество объектов, становясь само определенным типичным объектом эпохи: скажи, какое у тебя зеркало, и я скажу, кто ты.

Использовав в названии нашей статьи слово «зеркало», мы бы хотели подчеркнуть то, что зеркало - это инструмент, в который люди смотрят, чтобы увидеть себя. Однако, нередко, всмотревшись в это зеркало, они нередко обнаруживают там что-то иное, то, что не ожидают увидеть. На самом деле нас нет в зеркале, другими словами, мы видим то, что не существует.

Зомби, будучи достаточно сложным феноменом, являются отражением сразу множества явлений в нашей жизни, иногда запечатлевая, а иногда преломляя их. Так уж получилось, что чаще всего в образе зомби проявляются наши страхи и неуверенность в происходящем.

Именно поэтому в данном специальном номере мы попытались представить эту тему с разных сторон. Понимая, что к теме зомби обращались множество исследователей ${ }^{1}$ мы попытались затронуть те стороны его «существования», которые бы помогли нам как лучше понять суть этого феномена.

В любом случае, образ зомби в современной массовой культуре имеет слишком сложную природу и затрагивает самые разные стороны человеческой души. Огромное количество исследований, посвященных этой теме, не приближает нас к раскрытию тайны его феномена. Ученым самых разных областей знаний еще предстоит приложить много усилий, чтобы до конца постичь суть этого явления.

Объектом нашего исследования будет зомби. Но нас эта проблема будет интересовать в аспекте массовой культуры, так как является своеобразной лакмусовой бумажкой, изменяющей свой цвет под влиянием внешних раздражителей.

Даже близкое знакомство с феноменом зомби показывает, что явление это зарождается как реакция на внешние раздражители, с которыми субъекты сталкиваются. Поэтому нас будет «волновать» не только сами зомби, но в большей степени то, как мы их конструируем и то, как мы их встраиваем в

1 Поиск в электронном каталоге JSTOR по запросу «zombie» дает ссылки на 10476 наименований научной продукции. 
нашу культуру (в том числе и массовую). Тот факт, что представления о зомби генетически восходят к ряду африканских культов, заставляет нас прибегнуть методологически к постколониальной рефлексии. Нам существеннее понять не столько онтологию этого явления, сколько специфику тех форм, которые он приобретает в нашей культуре, т.е. гносеологию их существования. И эта трансформация в некоторой степени важнее чем изначальное явление, так как оно помогает нам взглянуть на самих себя. Метафора зеркала здесь оказывается, как нельзя кстати. Да и сами зомби весьма продуктивны в плане создания метафор. Как заявляет Т. Браун, «метафора является инструментом огромной концептуальной силы. Она дает ученому возможность интерпретировать естественный мир удивительным и продуктивным способом» (Brown, 2008, p. 14). Другими словами, она помогает нам перевести определенную информацию из области опыта, называемой исходной областью, в область, названную Брауном таргетированной областью (р. 18-19). При этом опыт, полученный в исходной области, может трансформироваться, теряя в некоторой степени начальную связь с исходным опытом.

\section{Зомби с привкусом сахара}

Не будет никаким преувеличением заявить, что у большинства людей слово «зомби» вызывает образ мертвеца, безучастно бредущего без всякой цели странной походкой ${ }^{1}$ и активизирующегося в присутствии человека, чтобы пожрать его плоть. Контакт с зомби превращает самого укушенного человека в зомби, теряющего все человеческое и также испытывающего страшный голод к человеческой плоти.

Во всех этих представлениях о зомби два момента являются наиболее знаковыми: их бездушность и страшный голод. Первый признак порожден безволием, отсутствием разума, а второй - страстной потребностью «вкусить жизнь».

Как ни странно, но именно эти два признака оказываются уж не столь вымышленными, так как образ зомби выкристаллизовался и сформировался на основе труда африканских рабов на сахарных плантациях на Карибах.

Эти плантации явились результатом страстного желания жителей Европы такого уникального продукта, как сахар. И хотя сахарный тростник, из которого и производят сахар, был известен в Старом Свете еще задолго до открытия Америки, начало культивации этого продукта в Новом Свете с использованием труда рабов-африканцев сделало этот продукт доступным широким массам в Европе. Правда, рабский труд использовался еще раньше на Мадейре и Канарских островах. И хотя производство сахара было достаточно продуктивным, оно не достигало того масштаба, которое приняло на Карибах. Кроме этого, на этих плантациях использовался только труд рабов мужчин, а контролирующим персоналом были, как правило, португальцы (Walvin, 2018, p. 30).

1 Английский вариант обозначения зомби «walking dead»- «бродящие мертвецы». 
Все это делало стоимость продукта очень высокой, ограничивая его использование элитой.

Несмотря на удаленность американских колоний, где также начали выращивать сахарный тростник, плантационное хозяйство приносило огромные прибыли, формируя сложную цепочку отношений между агрономическим сектором, перерабатывающим и производящим. При этом в общем процессе производства и потребления были задействованы самые различные силы и различные институты. В Новом Свете выращивали сахарный тростник, выжимали из него сладкий сок, вырабатывали кристаллы сахара, а оставшуюся черную сладкую жидкость - мелассу (патоку) - везли в Европу, где из нее производили ром, который затем поставляли в Африку, там его меняли на рабов или продавали, а на вырученные деньги покупали рабов, которых затем везли на плантации в Новый Свет и продавали там, вновь закупая сахар и мелассу, поставляемые в Европу.

Американский антрополог Сидни Минц, изучавший в 1948 г. жизнь на сахарных плантациях, оставил нам очень яркую картину всего происходящего в отдельных местах в Пуэрто-Рико:

\footnotetext{
Все время, пока я был в Баррио Хаука, мне казалось, что мы находимся на острове, плавающем в море тростника. Мне регулярно приходилось посещать поля, особенно во время сбора урожая (zafra), хотя и в другие периоды тоже. В то время большая часть работы все еще выполнялась исключительно вручную, без машин; срезание семян, посев, посадка, культивация, внесение удобрений, рытье канав, орошение, срезание и погрузка тростника - все это делалось руками. Иногда я стоял у линии резчиков, которые работали на страшной жаре и под большим давлением, в то время как надсмотрщик находился у них за спиной, а сзади за всем наблюдал на коне майордомо. Если кто-то знаком с историей Пуэрто-Рико и сахара, то хорошо представляет эту картину более ранней эпохи острова: мычание животных, крики майордомо, громкие выдохи людей, размахивающих своими мачете, пот, пыль и шум. Не хватало только звука кнута. (Mintz, 1986, p. XVIII)
}

Рост потребления сахара в Европе приводил к тому, что плантационные хозяйства нуждались во всё большем количестве рабов. Теперь на плантациях в Новом Свете работали не только взрослые мужчины, но женщины и даже дети. Младенцы, родившиеся на плантации, автоматически становились рабами, привыкая к плантационной атмосфере с первых дней своей жизни. Болезнь и смерть раба были не такой уж большой утратой, так как хозяин плантации легко мог заменить эту потерю новым рабом.

Как пишет Джеймс Уолвин,

Очевидным способом наведения и поддержания дисциплины - на работе или в помещениях для рабов - было физическое наказание. Однако плеть имела очевидные ограничения. Она могла быть контрпродуктивной, породить обиду и желание отомстить, а также причинить вред рабу. Кроме того, для многих видов рабского труда плеть была совершенно неуместна. В домашней обстановке ее нельзя было легко и просто использовать (но удары и подзатыльники применялись так же часто), хотя в рабовладельческих обществах существовала 
сложная дисциплина и рабы фактически удерживались на работе множеством дисциплин и вознаграждений, начиная от угрозы и реальности боли и заканчивая перспективами материального вознаграждения (какими бы ничтожными они ни были). Но было бы неправильно преуменьшать или игнорировать важность физического наказания как существенного стимула в функционировании рабовладельческих систем по всей Америке (Walvin, 1996, p. 49).

Насилие было главной отличительной характеристикой этого института. Оно начиналось даже еще до того, как раб попадал на плантацию: то есть с момента его пленения, содержания в кандалах взаперти, нередко клеймения, бесчеловечной транспортировки в трюме корабля, и т.д. Но и на суше его жизнь не становилась легче.

В этих условиях попытки сопротивления надсмотрщикам и владельцам плантаций были нередким явлениям. Правда шансов на выживание у сбежавшего бунтаря было немного. Если он и не погибал в сложных условиях джунглей, в которых скрывался, то рисковал быть пойманным специальными охотниками за рабами, устраивающими охоту на беглецов. И тогда его ждало неотвратимое наказание, по степени жестокости сравнимое со средневековыми пытками (Walvin, 1996, p. 50).

Чтобы подавить возможное сопротивление на плантации, надсмотрщики и майордомы старались сломить бунтарский дух рабов, сведя их существование до животного состояния. Даже такой одиозный сторонник рабства как ямайский плантатор Эдвардс Брайн1 отмечал:

В странах, где господствует рабство, главным принципом, на котором держится правительство, является страх: или чувство абсолютной необходимости принуждения, которое, не оставляя выбора действий, упраздняет все вопросы права (Bryan, 1806, vol. 4, p. 13).

Правда, эта критика касалась Франции и французских колоний, но в целом его слова можно было бы перенести и на все плантации Нового Света, да и не только на них.

Выжить в этих условиях можно было лишь при условии хороших физических данных, ну - или если втереться в доверие управляющего и начать продвигаться по социальной лестнице.

Ситуация осложнялась еще и тем, что рабы представляли собой аморфную массу, которая часто не могла найти общего языка, так как они принадлежали к разным племенами и были вывезены из разных регионов. Поэтому в подобных условиях они также порой оказывались враждебно настроены по отношению друг к другу. Атмосфера подозрительности, враждебности - нередкое явлением на плантации. И среди рабов шла острая борьба за доминирование, власть и т.д.

1 Эдвардс Брайн (1743-1800) был заметной фигурой на Карибах - он крупный плантатор на Ямайке, исследователь-натуралист, политик. Будучи пытливым по натуре, он оставил нам описание многих сторон жизни на Ямайке и других островах региона. См. о нем (Blouet, 2000). В своем многотомном труде, посвященном британским колониям в Вест-Индии он оставил описание и не которых культов, практикуемых африканскими рабами на плантациях. 
Найти опору в национальных традициях, родном языке и т.д. не всегда просто. Но были и некоторые культурные элементы, объединявшие все племена. Как правило, они касались ряда религиозных воззрений, сакральных практик, общей картины мира, с ее дихотомией сакрального и профанного и т.д. Еще больше возросла потребность в услугах знахарей, прорицателей, колдунов и т.д. Как ни странно, повысилось значение и рекреационных практик: танцев, песнопений и т.д. Часто эти практики были наполнены сакральным смыслом.

Так национальные традиции оказывались пассивной (а иногда и достаточно активной) формой сопротивления.

Британский колониальный чиновник, родившийся и работавший на Ямайке, политический деятель и ученый Эдвард Лонг (1734-1813) оставил некоторые указания на подобные практики. Он был одним из первых, кто начал говорить о «воскрешении мертвых». Правда, говорил он это в ином контексте, рассказывая про суеверия, распространенные среди африканских рабов и мулатов (креолов):

Наиболее чувствительные из них боятся сверхъестественных сил африканских obeab, или притворных заклинателей; часто приписывая те смертельные эффекты их магии, которые являются лишь естественным действием какого-то ядовитого сока или препарата, ловко применяемого этими злодеями. Но креолы полагают, что добродетели крещения или превращения в христиан делают их искусство совершенно неэффективным; и только по этой причине многие из них желают креститься, чтобы быть защищенными от Obeah. Не так давно на Ямайке некоторые из этих гнусных негодяев придумали то, что они называли танцем myal, и создали своего рода общество, в которое они приглашали всех, кого могли. Приманка заключалась в том, что каждый негр, посвященный в общество myal, будет неуязвим для белых людей; и, хотя внешне они могут выглядеть убитыми, колдун оbeah способен, по своему желанию, вернуть тело к жизни. Метод, с помощью которого этот трюк проводился, состоял из использования холодной настойки куста colalue, употребляемой после танцев, что и погружало участника в глубокий сон. В таком безжизненном состоянии он находился длительное время, не обнаруживая ни пульса, ни биения сердца, до тех пор, пока его не натрут другим настоем (который пока остается еще неизвестным белым). Эффекты от colalue постепенно проходят, тело возобновляет движение, и участник... просыпается, как от транса, совершенно не помня, что происходило с ними после танцев. Недавно, один из членов общества myal, желая уговорить своего друга стать одним из них, поведал ему о мощных свойствах, вызываемых myal, и в частности, что оно делает тело неуязвимые для пуль, так что Белые были бы не в состоянии навредить ему, даже если бы стреляли тысячу раз. Его друг выслушал с большим вниманием, но усомнился в истинности сказанного, тогда, после некоторого замешательства, он предложил ему, что, если тот готов выстоять выстрел, то он был бы рад участвовать в эксперименте и, если все окажется, как тот говорил, тогда он сам бы легко согласился стать членом myal. Тот согласился на эти доводы, не представляя себе, вероятно, к чему приведут в конечном итоге его убеждения. Приготовившись, он встал, чтобы встретить выстрел. Его друг выстрелил и убил его. Это происшествие и обстоятельства, приведшие к этому, вскоре стали широко 
известны, и, в скором времени, принесли их жрецам и их искусству дурную славу среди всех новообращенных (Long, 1774, pp. 416-418).

Э. Лонг заявляет также, что нередко снадобье, способное постепенно убивать человека, жрецы могли применить против тех собратьев, которые пользовались хорошим расположением со стороны хозяев или отдалялись от своих собратьев. Были случаи, когда отрава была применена и против плантаторов (р. 418).

Подробно повествует Лонг о восстании рабов против белых плантаторов на Ямайке в 1760 г. под предводительством Таки. Вождем восстания был старый жрец obeah, подстрекавший рабов к выступлению против белых и обещавший им неуязвимость от пуль угнетателей. Он и его сторонники убеждали восставших, что с помощью Таки рабы обретут способность противостоять пулям. Но жрец был схвачен в момент совершения им обряда обретения неуязвимости и повешен прямо в ритуальном облачении, состоящим из «перьев, зубов и других магических предметов. И когда другие увидели, что его повесили с такой легкостью, несмотря на хвастливые заверения в могуществе и силе, то многие изменили свое мнение и решили не присоединяться к восставшим собратьям» (р. 452).

Жизнь на плантации - всеобщая атмосфера страха. При этом в состоянии страха могут находится не только рабы, но и рабовладельцы. Мы уже писали выше, что Лонг упоминал о нескольких отравлениях белых плантаторов, совершенные рабами. Сложно сказать, так ли это было, но в отдельных случаях страх мог парализовать жизнь плантации. Об одном таком случае сообщает уже упомянутый Э. Брайн, услышавший эту историю от одного из плантаторов, заслуживающего доверия:

«Вернувшись на Ямайку в 1775 г. после долгого отсутствия, он обнаружил, что многие рабы умерли, а половина из выживших совершенно ослабли и распухли, и с каждым днем им становилось только хуже. После его приезда смерти продолжались, и в один из дней было похоронено сразу два или три человека, а другие заболели, и им становилось с каждым днем все хуже. Были перепробованы все медицинские средства, но все безрезультатно... Смерти продолжались еще двенадцать месяцев, и плантатор стал сильно подозревать, что не обошлось без вмешательства obeah, о чем говорили доктор и другие белые на плантации, тем более что всем было известно, что эта практика распространена на этой части острова, особенно среди негров из страны Папа или Попо. Но подтвердить свои подозрения он не мог, так как все больные отрицали, что как-то могли быть связаны с этими культами. Через какое-то время пришла больная негритянка, заявившая, что чувствует, что уже долго не проживет и ощущает своим долгом раскрыть перед смертью большой секрет. Она сообщила истинную подоплеку этих беспорядков, полагая, что это поможет уничтожить причину несчастий, выпавших на долю ее собратьев-рабов. Она рассказала, что ее мачеха (женщина из страны Попо, которой уже больше 80, но она все еще выглядит здоровой и активной) наслала на нее порчу (Obi), и то же самое она сделала с теми, кто недавно умер; и что старуха практикует Obi уже очень давно. Другие негры, узнав про признание, поспешили предстать перед своим господином и подтвердили правдивость заявлений, добавив, что 
она занимается этим делом с момента ее прибытия из Африки, и что она наводила ужас на все окрестности. После этого, он и шесть белых слуг, поспешили к ее дому и, выбив дверь, увидели, что весь ее дом под самую крышу и все стены увешаны предметами ее занятий, состоящих из лоскутов, перьев, кошачьих скелетов и тысячи других подобных вещей. Продолжив исследование хижины, они обнаружили глиняный горшок или кувшин, плотно закрытый. В нем содержалось огромное количество круглых шариков из земли или глины, различных размеров, большие и малые, побелевшие с внешней стороны, и по-разному слепленные, некоторые с волосами и лохмотьями, или перьями всех видов, и сильно перевязанные бечевкой, другие смешанные с верхней частью черепа кошки или облепленные кошачьими зубами и когтями, другие с человеческими или собачьими зубами и какими-то стеклянными шариками разных цветов; было также много скорлупы, заполненной вязким или липким веществом, которое он не захотел исследовать, и множество мешочков с содержимым из разных предметов, сведения о которых не он может вспомнить по причине давности времени. Дом был немедленно снесен, и со всем его содержимым предан огню на фоне общего ликования других негров. Что касается старухи, он отказался доставить ее в суд, как того требовало законодательство острова, который бы осудил ее на смерть, но из принципа гуманности отдал ее в руки испанцам, которые с радостью приняли ее и увезли на Кубу. С момента ее ухода, его негры воспрянули духом, и болезнь больше не распространялась. Общая сумма его потерь в течение 15 лет, предшествующих раскрытию тайны, по вине исключи тельно obeah оценивается им по меньшей мере в 100 негров (Bryan, Vol. 1, pp. 89-91).

Как видим, происходящим на плантациях были озабочены не только африканские рабы, но и белые плантаторы. Да и сам «просвещенный» Э. Брайн рассматривал все эти вопросы вполне серьезно, что уж говорить о простых плантаторах или мулатах и белых надсмотрщиках.

Интересно и то, что слухи о «сверхъестественных способностях» возвращаться к жизни изначально фигурировали не на основе толков об «оживших мертвецах» - безвольных обезличенных рабах, возвращенных к жизни для выполнения тяжелого труда, а на актах сопротивления, способности противостоять насилию со стороны белых. Нет ничего удивительного в том, что этими способностями наделялись члены культа myal, участвующие в коллективных танцах.

\section{Танцы со смертью}

Как указано выше, в условиях невозможности сохранять идентичность, как правило, именно танцы и песнопения становятся основным инструментом сопротивления. Будучи совмещенными с различными трансовыми техниками, они превращаются в мощное оружие борьбы. Круговые танцевальные движения для достижения трансовых состояний хорошо описаны во многих культах в различных милленаристских движениях (Andersson, 2008; Davies, 2007; Henson, 2002; La Barre, 1970; Mooney, 1896).

Как показывает история подобных движений в других уголках мира, трансовая танцевальная практика начинает играть решающую роль в тех 
случаях, когда другие формы сопротивления оказываются менее эффективными. Важно понимать, что все эти милленаристские культы, важнейшей частью которых были идеи о возрождении мертвых, возникают в кризисные периоды. Это касается и культа Таки Онкой в Центральных Андах (1564-1572), движение племени коса в Южной Африки (1856-1857), Пляска Духов в США в конце XIX в. и многих других в различных регионах мира. В этом плане происходящее на плантациях ничем не отличалось от иных религиозных движений по всему миру. На это указывал еще в 50-е гг. XX в. американский антрополог Энтони Уоллас (1923-2015), который, собственно, и сформулировал теорию ревиталистских движений (движений по возрождению культуры). В своей программной статье он утверждал, что многие ныне существующие религии являются по сути отголосками подобных движений, сложившихся в период кризиса - «в результате видении нового образа жизни людьми, находящимися в состоянии сильного стресса» (Wallace, 1956, p. 268).

Он же выделил пять этапов ревиталистского движения, которое проходит различные стадии - от стабильного состояния до кризисного явления, трансформации традиционной культуры, пересмотра картины мира, ее переформатирования и возвращения в стабильную ситуацию (р. 268). Практически все эти этапы (кроме первого) имели место на плантации. Там был личностный кризис, потеря ценностных ориентиров в новых условиях плантационного хозяйства и попытка пересмотреть и даже перестроить существующую картину мира на основе старых ценностей и новой культурной ситуации.

Естественно, что этот пересмотр в условиях жесткого доминирования с внешней стороны (плантаторов и их прислуги) мог быть осуществлен лишь с помощью особых инструментов традиционной культуры. Принципы «возрождения из мертвых» и «неуязвимость» стали играли важную роль в новой картине мира.

Правда, когда речь шла про myal и первоначальных практиках сопротивления obeah против плантационного рабства, еще не встречалось упоминания про зомби. Вместе с тем, некоторые авторы подробно описывают применение рабами различных снадобий, вызывающих временную потерю сознания и имитацию смерти. Как нам кажется, именно этот аспект ревиталистского движения был основополагающим для дальнейшего формирования образа зомби. Он давал надежду на выход из кризиса, пусть довольно иллюзорным путем. В иных условиях этот процесс протекал бы в более масштабной форме, вовлекая в свое движение многочисленные массы рабов. Однако замкнутый мир плантации, прикрепленность рабов к определенной асьенде - плантационному хозяйству не давало возможности более широкому распространению информации. Здесь следует учесть и тот факт, что некоторые варианты подобных культов были ограничены конкретными островами. Карибские острова находились во владении нескольких держав - прежде всего Испании, Франции и Великобритании, т.е. между ними существовали и государственные, и культурные границы. 
Важно, что подобные движения являются своеобразным откликом на аккультурацию (Sanford, 1974). Другими словами, myal и obeah - наследие не только некоторых африканских культов - это африканские культы, прошедшие трансформацию под влиянием европейских культур. И здесь усматривается не только возможное влияние христианства на идею возвращения из мира мертвых («смертью смерть поправ»), но и выстраивание европейцами особой плантационной системы, с ее порядками, традициями, нормами, предписаниями, запретами, системой наказаний и поощрений и т.д. Эту мысль о роли Европы очень хорошо выразил уже упомянутый С. Минц:

Почему Европа? Потому что эти островные плантации - изобретение Европы, заморские эксперименты Европы, многие из которых были успешными (насколько это было известно европейцам); и история европейских обществ в некотором смысле параллельна истории плантаций. Можно оглянуться вокруг и увидеть плантации сахарного тростника, имения кофе, какао и табака, и так же можно представить себе тех европейцев, которые сочли перспективным создать их, инвестировать в их создание и привезти огромное количество людей в цепях из других стран для работы на них. Эти последние будут если не рабами, то людьми, которые продают свой труд, потому что им больше нечего продавать; которые, вероятно, будут производить вещи, основными потребителями которых они не являются; которые будут потреблять вещи, которые они не производили, и в процессе получать прибыль для других в других местах. (Mintz, 1986, p. XXIV).

Привезенных рабов изначально ввергли в состояние кризиса, личностного, общественного и т.Д. Их лишили будущего, и выходом из этого состояния могло быть или бегство, или те культы, которые дарили им пусть и иллюзорную, но надежду. В этой схеме смерть становилась обнадеживающим «выходом», дарующим свободу. Ведь раб уже оказывался на краю, который являлся тонкой гранью, отделяющей его жизнь и жизнь его сотоварищей от смерти. Эта идея оказывалась пугающей и для самих колонизаторов. Именно поэтому жрецы myal и obeah оказываются символами чего-то непонятного ${ }^{1}$. Они превратились в антитезу прогресса, науки и всего того, что олицетворял прогресс цивилизации:

Над другими жрецами obeah, захваченными в то время, были проведены различные опыты с электрическими машинами и волшебными фонарями, но с очень небольшим эффектом, за исключением одного, который, получив несколько очень сильных ударов, признал, что «оби его хозяина сильнее его собственного» (Bryan, Vol. 1, pp. 92).

Невольно обращаешь внимание на то, что автор охотно сообщает нам информацию о том жреце, кто признал величие европейской науки, но остальные, которые не поддались «влиянию» европейской науки не удостоились упоминания.

1 Мы здесь не рассматриваем жреца как символ связи с нечистой силой, персонаж, одержимый дьяволом. Хотя нередко это было типичным явлением, нашедшим свое отражение в различных аспектах западной культуры того времени. 
Именно поэтому первой метафорой зомби оказывалась не метафора «ходячего мертвеца», а метафора бунтаря, обладающего особой силой, «недоступной» для понимания образованному цивилизованному европейцу.

Многие африканские религиозные практики оказались теми инструментами, которые помогали сохранять определенную идентичность и сулили некоторую защиту от внешних и внутренних сил.

Вместе с тем, следует понимать, что вся сложность феномена зомби заключается в том, что он был совершенно новым явлением, родившимся в тяжелых условиях плантационного хозяйства. Именно поэтому он постоянно претерпевал изменения, так как трансформировалось и само плантационное хозяйство. Запрет работорговли, принятый британскими правительством в 1807 г. сократил приток рабов в колонии, хотя и не уничтожил его совсем. Другие страны еще продолжали привозить рабов в свои колонии.

\section{Зомби как отражение нового кризиса плантационного хозяйства}

Прекращение притока новых рабов постепенно приводило к стабилизации жизни на плантации. Раньше рабов привозили из разных мест Африки, они говорили на разных языках, у них были разные традиции, различные культы и т.д. Приход новичков вносил диссонанс, происходила внутренняя борьба, в которую нередко оказывались втянутыми и сами рабовладельцы. Обвинение друг друга в колдовстве, подстрекательству к бунту было обычным явлением. Новички из других племен оказывались чужими. Среди отдельных народов и на родине не всегда царил мир и покой. На плантации вспоминались прошлые обиды и конфликты. Но после прекращения работорговли все изменилось. Во многом это произошло потому, что на плантации выросло новое поколение рабов, родившихся здесь, не знавших других условий жизни.

Плантация для них оказывалась особой вселенной - изолированным миром со своими порядками, нормами и т.д. Теперь плантация нуждалась не только в рубщиках сахарного тростника. Здесь нужны были и другие специалисты. Все эти моменты очень хорошо отражены в одном художественном произведении, написанном в начале XIX в. человеком, хорошо знакомым с жизнью на плантации. По мнению автора, стремление рабовладельцев упорядочить жизнь в своем владении, приводила к необходимости делить рабов на группы, создавая определенную стратификацию плантационного общества даже внутри однорасового состава. Еще с детства ребенка приучали быть частью определенного коллектива - команды (gang). Маленькие детей, организованных в команду, выводили на поля под управлением старый 
опытной женщины, вооруженной маленьким кнутом. Эта команда называлась «пикенини» ${ }^{1}$ (Marly, 1828, p. 93).

Были и другие команды: каменщиков, плотников, столяров, лудильщиков, кузнецов и т.д. (Marly, p. 94). Как правило, во главе этих команд стояли люди смешанных кровей: мулаты, самбо, метисы (mustee), мастефины ${ }^{2}$ или квартероны. К этим людям иначе относились на плантации, их не посылали в поле и никогда не наказывали. Пользуясь привилегированным положением на плантации, они считали себя выше по отношению к чернокожим рабам. Возникающие ссоры или споры между ними и рабами были обычным явлением (Marly, p. 94).

Но и между разными командами также возникали время от времени конфликты. Все это создавало атмосферу напряжения, в которой многие мелкие сообщества пытались получить для себя определенное преимущество. Различные религиозные организации нередко старались добиться этого, используя старый проверенный метод - страх перед неизвестным. С отменой рабства общество еще больше стратифицируется, а плантационное хозяйство приходит в упадок. Теперь в кризисном состоянии оказываются не только черные рабы, но и белые плантаторы, и смешанное население.

Смещение акцента от сопротивления белым к доминированию над собственными «соплеменниками» породило и новые методы достижения влияния. В этих условиях «воскрешение из мертвых» и «невредимость», полученная для борьбы с белыми, вытесняется другими формами воздействия, в которых зомби, или «воскресший человек», призванный влачить рабское положение, работая на другого человека, оказывается привычным явлением.

\section{От бессмертного колдуна к бессмертному зомби}

Одновременно и фигура колдуна трансформируется, все сильнее превращаясь в ужасного, отвратительного и крайне негативного персонажа. Покинув страницы плантационной литературы (дневников, травелогов, художественных произведений), образ отвратительного колдуна становится центральной фигурой многих западных произведений, особенно в США. Даже такой писатель, казалось бы, с симпатией относящийся к представителям других рас, как Г. Лонгфелло публикует в 60-х гг. поэму под названием «Жиль Кори с Салемской фермы» (Longfellow, 1868, pp. 97-179). В центре история индианки Титуба реального персонажа - одной из жертв охоты на ведьм в Салеме (шт. Массачусетс). У Лонгфелло она превращается в злую колдунью, желающую навредить своим хозяевам (рр. 103-104). По ее словам, она может принести вред не только людям, способна вызвать падеж скота и неурожаи кукурузы, кораблекрушения, торнадо или пожары. Но главное, она насылает месть на своих врагов, которые

\footnotetext{
1 Пикенини (pickenini, pickaninny) - термин, вошедший в английский язык из креольского. Он употреблялся по отношению к маленькому чернокожему ребенку. Этимологически восходит к порт. "pequeno" «малыш».

2 Мастифин (Mustiphini) - человек рожденный от белого и метиса.
} 
смотрят на нее как на рабыню, однако в реальности сами являются ее рабами (р. 104). Интересно и то, что в произведении Лонгфелло грань между индианкой Титубой и ее африканскими корнями как бы стирается. Он называет ее индианкой, однако, постоянно намекает на ее африканские корни.

В третьей сцене она разговаривает с одной из девушек, у которой постоянные видения. В одном из них девушка видит таинственный остров и колдуна, совершающего какие-то магические действия над умирающей женщиной. Титуба поясняет ей, что это ее родной остров Сан Сальвадор, а мужчинаколдун - ее отец, обладающий сильной магией - оби. Умирающая женщина это его жертва.

И это пишет человек, который около 10 лет назад создал «Песнь о Гайавате» (1855), проникнутую глубокой симпатией к индейцам.

Романом о жутком африканском колдуне отметился и другой «любитель» произведений об американских индейцев - Майн Рид. В «Маронах», повествующем о жизни на сахарной плантации на Ямайке читатель обнаруживает жуткий образ африканского колдуна Чакры. Как нам кажется, то, как Майн Рид повествует о колдунах (myal и obeah), во многом почерпнуто им из литературы XVIII в., часть из некоторых трудов мы упоминали выше. Поэтому, нарисованная им картина вторична. Вместе с тем, она хорошо показывает настроения читающей публики. В описании Майн Рида мы видим опять противопоставление цивилизации и дикости (Mayne Reid, 1, pp. 17-19). Дикость представлена такими персонажами как Чакра - получеловек/полузверь; полуживой/полумертвец. Даже после того, как его убивают, привязав цепями к пальме на вершине горы, он возвращается к жизни:

\begin{abstract}
Зачем удивляться! Он же мертв, разве ты не знаешь, что он myal? Myal умеет возвращать к жизни мертвого. Можешь быть спокойна, Чакра отлично все это знает. Его нельзя убить! Никто не в силах его умертвить: ни белый, ни черный. Пусть в него стреляют пулями, пусть вешают за шею, отрубят голову - он снова оживет. Его пробовали прикончить, тебе это известно. Его морили голодом. И он умер от голода и жажды. Ворон Джон выклевал ему глаза, склевал мясо с костей старого Чакры. И остались одни голые кости. А все-таки Чакра жив! Видишь, у него новые кости, новое тело. Ты видишь его? И он все такой же сильный и жирный, как всегда (vol. 2, p. 193).
\end{abstract}

Традиция представления африканского жреца или колдуна ужасной кровожадной фигурой продолжается и во многих других произведениях второй половины XIX в. Типичным примером такой культурной парадигмы может быть произведение Сэра Спенсера Сент. Джона - руководителя дипломатического представительства Великобритании в Гаити в 1871-72 гг.

В труде «Гаити, или Черная республика» он уделил большое внимание культам вуду, описывая их как очень дикие и даже связанные с каннибализмом (St. John, Spencer, 1884, pp. 182-228) ${ }^{1}$.

1 В американском издании 1889 г. (St. John, 1889) к уже имеющейся главе «Вуду и каннибализм» (pp. 187-231) появляется дополнительная глава «Каннибализм» (pp. 232-256). 
Bсе это хорошо демонстрирует то, что изначально мотив возрождения из мертвых в восприятии жителей Европы и США в большей степени связывался с образом жреца - он был субъектом этого превращения. Он мог или себя вернуть к жизни, или проделать эту операцию с другими.

Это указывало на глубокую пропасть между миром афроамериканцев ${ }^{1}$ и белых. И не даром, в американском издании так много уделено внимания африканским культам на Гаити и каннибализму (1889). Не стоит забывать, что США еще не оправились от Гражданской войны между Севром и Югом, а вопрос рабовладения и рабства был одним из основных в этом конфликте. Американцы пристально всматривались в «лицо» нового полноправного члена общества, так же как оно активно присматривалось и к другой проблеме коренному населению Америки. В данном процессе наблюдения и осознания были слышны разные голоса. Не случайно роман Гарриет Бичер-Стоу «Хижина дяди Тома» (1852) получил огромную популярность в США. Одновременно в «Приключениях Тома Сойера» (1876) мы видим двойственное отношение к представителям различных расовых групп: к афроамериканцу с симпатией, а к индейцу с подозрительностью и недоверием.

Как нам кажется, именно это внимание западного общества к данной теме, его видение или даже точнее конструирование Чужого сыграло важнейшую роль в создании образа зомби в западной массовой культуре. Можно с уверенностью сказать, что, покинув «родные» берега, зомби зажил в США и в Европе собственной жизнью, становясь символом нового мира.

\section{Я милого узнаю по походке}

Покинув «родные» берега, зомби становится важной частью современной массовой культуры. Приобретя его, западное общество уже не может от него отказаться, аккумулируя в образах зомби все спектры и все оттенки своих страхов и опасений, воплощенные в виде многочисленных метафор. Именно эти аспекты зомби мы и постараемся раскрыть дальше.

Зомби, как изначальный элемент культуры Карибских народов, оказывается частью современной мировой культуры, но при переходе из исходной области образ зомби трансформируется в ряд других нарративов, приобретая новые свойства и качества:

В образе зомби есть много точек притяжения, и в период, когда зомби, похоже, проникают в популярную культуру и появляются в научной литературе, существует, возможно, столько же способов воспринимать зомби и оценивать их, сколько существует людей, которые их пытаются оценивать. Среди них писатели, кинорежиссеры, теоретики культуры, подростки, философы и масса фанатов, у каждого из которых есть свое представление о том, что такое зомби, что является основополагающим текстом о зомби и почему стоит исследовать

1 Мы используем здесь термин «афроамериканцы» не только по отношению к чернокожему населению США, но и по отношению ко всем потомкам африканцев, привезенных в качестве рабов в Америку (Южную, Центральную и Северную). 
зомби. Поскольку идея зомби распространяется так широко и во многих областях, он стал очень знаковым персонажем, участвующим в повествованиях о теле, о жизни и смерти, о добре и зле; он указывает жестами на инаковость, расизм, расовые различия, неизбежность и незыблемость. Таким образом, он переносит нас на «другую сторону» в область отчуждения, смерть и то, что хуже смерти: состояние нежити (Webb \& Byrnand, 2017, p. 112).

Дж. Вебб и С. Бирнанд забывают упомянуть еще одну очень важную, с нашей точки зрения, метафору, которая напрямую связана с такими темами, как расизм и расовое неравенство, - безволие и обезличивание, которое в отдельных случаях оказывается страшнее самой смерти.

Некоторые исследователи идут еще дальше. Для многих зомби это метафора «чудовищности капиталистического мира», превращающего человека в свой бездушный придаток (Morissette, 2013; Newitz, 2006; Shaviro, 2002). Как полагает американский философ С. Шавиро,

Вампирский капитал может извлекать свой прибавочный продукт только путем организации своих легионов зомби-рабочих. И по мере развития и расширения капитализма эти легионы должны организовываться во все больших масштабах. Девятнадцатый век с его классическим режимом промышленного капитализма был веком вампира, но сетевое общество конца двадцатого и двадцать первого веков характеризуется скорее нашествием зомби (Shaviro, 2002, p. 282).

Собственно, в этом высказывании нет ничего удивительного. Еще раньше Ж. Делёз и Ф. Гватари утверждали, что

\begin{abstract}
Предприятие смерти - это одна из главных и специфичных форм поглощения прибавочной стоимости в капитализме. Это направление как раз и обнаруживается психоанализом, преобразовываясь инстинктом смерти - последний теперь является не более чем чистым молчанием в своем трансцендентном отличии от жизни, но тем не менее он распространяется по всем имманентным комбинациям, которые формирует с самой этой жизнью. Имманентная, распространившаяся, поглощенная смерть - таково состояние, в которое переходит при капитализме означающее, пустая клетка, которую перемещают то туда, то сюда, чтобы затыкать шизофренические лазейки и перекрывать пути ускользания. Единственный современный миф - это миф зомби, умерщвленных шизофреников, готовых к работе и возвращенных к рассудку. (Делёз \& Гваттари, 2008, p. 527).
\end{abstract}

Есть и такие исследователи, которые видят в зомби отражение разрыва между обществом и природой (Moles, 2014). Так американская исследовательница К. Олофф полагает, что зомби «является экологической фигурой, кодирующей разрыв между людьми и их природной средой, вызванный капитализмом, экономической системой, которая в первую очередь зависит от «принижения или обесценивания природы» (Oloff, 2012, p. 31). Тезис о «принижения или обесценивания природы» принадлежит отнюдь не ей. Она почерпнула его у британского исследователя индийского происхождение У. Мукерджи (Mukherjee, 2010, р. 66), который в свою очередь апеллирует к «Капиталу» Маркса. 
Как видим, здесь экологический посыл тесно переплетается с постколониальным и антикапиталистическим. Как заявляет видный американский теоретик Дж. Коен, занимающийся проблемами «монстрофикации» современной массовой культуры, «зомби являются воплощением колониальной истории и зарождающегося капитализма» (Cohen, 2017, p. 383).

Но у зомби есть еще одна прочная нить, связывающая их с экологическими проблемами - многие произведения готического жанра тесно связаны со страхом - нередко страхом перед природной стихией, а также чем-то неизведанным, что таит в себе природа:

Готическая литература настолько одержима страхами всех типов, что готика служит хорошей иллюстрацией для понимания того, как многие авторы независимо от времени их написания - отображали страхи и тревоги, связанные с миром природы (Hillard, 2009, p. 689).

Эту связь Коен называет «серой экологией», по аналогии с серым цветом сумерек, являющихся своеобразным символом самих зомби (Cohen, 2017).

В образе зомби скрыты и наши страхи перед развитием науки. Непродуманные действия ученых, вышедшие из-под их контроля, могут привести к непредсказуемым последствиям, превратив людей в зомби. Эта массовая зомбификация населения, порожденная учеными, - еще один из вариантов человеческих страхов перед неизвестным (Fehrle, 2016; Newbury, 2012, p. 89). Не стоит забывать, что современный кинематограф активно эксплуатирует тему искусственного происхождения зомби. В фильме «Я - легенда» (2007, реж. Р. Лоуренс), снятом по книге Ричарда Мэтисона (Matheson, 2007), разработанное учеными лекарство от рака вызывает пандемию, превращая людей в зомби. В сиквеле «Обитель зла» (Resident Evil, 2002, 2004, 2007, 2010, 2012, реж. П. Андерсен) мы видим почти схожий сюжет - огромная секретная корпорация, занимающаяся вирусологией, оказывается причиной пандемии, когда вирус выходит из-под контроля, и люди превращаются в зомби. В этом во многом повинен искусственный интеллект, управлявший лабораторией.

Современная пандемия «Ковид-19» хорошо демонстрирует, как быстро слухи об «искусственном» происхождении болезни завоевывает ума населения (Kormann, 2021; Kramer, 2021; Lawton \& Marshall, 2021; Maxmen \& Mallapaty, 2021; Шторм, 2020; Яшлавский, 2021). Конечно, приведенные ссылки на новостные ленты, появившиеся в различных медиа, лишь маленькая толика о том, как различные слухи владеют умами людей в разных уголках Земли, управляя их эмоциями и поступками.

И, наконец, символически зомби оказываются востребованными тропами в совершенно новой области, которую еще недавно было бы трудно предположить в связи с ними, но теперь все чаще она становится актуальной в различных исследованиях, - зомби порнография. Важно понимать, что речь идет не обязательно про сцены, изображающие откровенные эпизоды секса у зомби, важнее другое, что 
Зомби родственны квир-меньшинствам: они всегда уже являются квази-порнографическими телами, открытыми миру неожиданным или нетрадиционным образом; они пополняют свою численность посредством заражения (в торговых центрах, общественных парках, местном баре, в силовых структурах, большом городе, маленьком городке или семейной спальне); и они символизируют мир, захваченный алчным множеством, мир без будущего (Mcglotten \& Vangundy, 2013, p. 102).

По мнению этих авторов в определении «зомби-порно» важно то, что оно

касается не только сексуализированных изображений зомби, но и того, как зомби-секс выступает в качестве материальной практики, которая может помочь усилить критический анализ того, что является непристойным в данный политический момент (аскетизм, социальный отказ, конфликтные спекулянты), или того, какой политический потенциал все еще может быть связан с формами секса или латеральными действиями, которые не рассматриваются как серьезные политические позиции или агентства (Mcglotten \& Vangundy, 2013, p. 104).

Под термином «зомби порно» Ш. Макглоттен С. Вангунди понимают не само порно как таковое, а наше восприятие зомби как нечто, выходящее за грани, что согласуется с позицией швейцарского исследователя Й. Ферле, заявляющего, что «зомби не признают границ» (Fehrle, 2016).

Определяя зомби через квир, авторы показывают, что зомби находятся за гранью привычного, их тела трансгрессируют, нарушая неписанные нормы. Выйдя за рамки человеческого, утратив личность, они как бы утрачивают право на существование, превратившись в объекты, угрожающие нашему существованию. Но почувствовав тепло наших тел, они становятся субъектами, чьи действия регулируются внутренними потребностями или внутренней программой, которую, однако, они не могут контролировать. И эти свойства зомби сближают их с киборгами или андроидами - механическими объектами, похожими друг на друга, не имеющими личности и управляемыми только программой. В отдельные моменты они также могут нести опасность человеку, несмотря на «три правила», запрещающие вредить ему, как это было показано в фильме «Я, робот» (2004) Алекса Пройаса (Proyas, 2004).

В этом фильме, написанном по мотивам рассказов А. Айзимова (Asimov, 2004), очень хорошо изображены страхи, которые испытывает главный герой - детектив Дэл Спунер - перед лицом быстро меняющейся реальности. Безликая масса роботов, постепенно заменяющих человека, пугает героя. По его мнению, с помощью бездушных машин человек постепенно вытесняется из активной жизни, сам становясь маргиналом, утрачивая личность.

Схожую ситуацию можно наблюдать и в настоящий момент. Многих людей настораживает кажущаяся «потеря» индивидуальности, условное «информационное чипирование» с помощью QR-кодов. И хотя это мало напоминает «превращение» человека в зомби, то есть прямое «зомбирование», но связь всех этих процессов с вакцинированием и информационным кодиро- 
ванием, якобы вытесняющим личность человека или заменяющая ее (его имя, фамилию, пол, возраст и т.д.), пугает население во многих странах мира.

Фильм «Я, робот» поднимает еще одну проблему - замещение человека машиной может происходить и не во вне, а внутри человека. Недаром в этом фильме у главного героя Спунера некоторые части тела механические. Он и сам в некотором смысле машина. Сколько частей тела нужно заменить в нем, чтобы он превратился в машину? Станет ли он роботом, или останется человеком? Все эти вопросы касаются как онтологии, так и гносеологии существования человека.

Вся его бытийность завязана на стремлении к безопасности и в то же время на стремлении к выходу за пределы, ограничивающие его жизнь. Во многом следствием этого является развитие науки и техники, нацеленное на преодоление границ: пространственных, темпоральных, функциональных и т.д.

Зомби, роботы, киборги, андроиды находятся по ту сторону границы там, где человеческое существование невозможно. Конечно, можно и иначе трактовать этот посыл. Многие полагают, что человеческое бытие после смерти возможно:

21. Ибо, как смерть через человека, так через человека и воскресение мертвых.

22. Как в Адаме все умирают, так во Христе все оживут (1 Кор. 15, 21-22).

Роботы и киборги не требуют веры, существование их детерминировано самим уровнем развития науки. Американские исследовательницы Сара Джульет Лауро и Карен Ембри заявляют в своем «Манифесте Зомби», что зомби в значительной степени символизирует постчеловеческое бытие:

непримиримое тело зомби (и живое, и мертвое) поднимает вопрос о недостаточность диалектической модели (субъект/объект) и предлагает, с помощью своей собственной негативной диалектикой, что единственный способ по-настоящему стать постчеловеком - это превратиться в антисубъект (Lauro \& Embry, 2008, p. 87).

Эта фраза из их «Манифеста» приобретает новый смысл, если вспомнить «Призрака в доспехах» - и аниме (Shirō, 2017), и одноименный фильм (Sanders, 2017), в которых личность человека оказывается заключенной в кибернетическом теле. Подобный субъект превращается в полную противоположность зомби. У него есть личность, но тело уже нечеловеческое. Зомби обладает человеческим телом, но его субъектность под большим вопросом, так как у него нет личности. И в случае с кибернетическим телом не все так просто. Личность Миры Киллиан (Mira Killian) оказывается в значительной степени некоторой условностью, так как она не помнит своего прошлого. Она есть лишь то, что ей внушили. Таким образом, человек ли она, или просто запрограммированная машина для убийств? Да и само еe имя Киллиан (Mira Killian) указывает нам на ее предназначение убивать - Kill (анг. «убивать»). По сценарию она стремится убивать, это желание манит ее, как теплая плоть 
живого тянет зомби. Правда, убивает она «плохих», сражаясь со злом, но дело все-таки в том, что ею руководит тяга к сражению, битве, поединку, оказавшаяся фундаментальной частью ее сущности.

\section{Заключение}

Таким образом, зомби превращается в уравнение с множеством неизвестных, которое некоторые авторы пытаются решить путем простого подставления различных значений. Но сведение феномена зомби лишь к одному значению контпродуктивно. Выйдя за пределы колониальной и постколониальной истории, зомби начали жить по своим законам, порождая новые смыслы. И то, что они оказываются метафорами, указывающими на самые различные значения (Lauro \& Embry, 2008, pp. 85-86), лишний раз подтверждает это. В этом нет ничего удивительного, так как зомби существуют сразу в двух плоскостях: онтической и хонтической. Они как бы существуют, но их нет. Их бытийность мы можем описать, но это описание будет являться лишь отражением наших вымышленных представлений о них. И если даже речь будет вестись об исторических зомби, т.е. тех объектах культуры, которые якобы имели место в некоторых странах Карибского бассейна, эти описания всего лишь некие домыслы.

Зомби, стал частью современной массовой культуры. Он оказался, по мнению Делёза и Гватари, единственным мифом современности (2008, р. 527). Можно легко предположить, что метафоричность зомби будет продолжать развиваться, принимая все новые и новые формы. И дело здесь не только в уникальности этого явления. Представления о зомби явились реакцией на кризисные процессы, происходящие в обществах (на плантациях, на фабриках, в условиях перехода общества к новым технологиям, научным открытиям). Кризисные явления никуда не исчезнут, а с ними будут появляться и новые метафоры, «порожденные» зомби. Зомби уже давно вышли из-под контроля, «захватывая» все больше смыслов и значений.

Но меняется и общество, поэтому осмелимся предположить, что зомби пойдут по пути «гуманизация», все больше возвращая в себе человеческие черты, как, например, в фильме «Тепло наших тел» (Warm Bodies, 2013, Дж. Ливайн), в котором описан зомби, способный любить и сопереживать ${ }^{1}$. Первый шаг сделан, зомби пошел навстречу. Готовы ли мы «принять» его, отнестись к нему по-человечески?

\section{БЛАГОДАРНОСТЬ}

Авторы выражают благодарность д.филол.н. Е. Е. Завьяловой за ценные замечания и рекомендации по данной статье.

1 У него даже есть имя, правда, это всего лишь одна буква «Р», но и это уже большой шаг вперед по пути обретения личности. 


\section{Список литературы}

Andersson, R.-H. (2008). The Lakota ghost dance of 1890. University of Nebraska Press.

Asimov, I. (2004). I, robot. Bantam Books.

Blouet, O. M. (2000). Bryan Edwards, F.R.S., 1743-1800. Notes and Records of the Royal Society of London, 54(2), 215-222.

Brown, T. L. (2008). Making Truth: Metaphor in Science (1st edition). University of Illinois Press.

Bryan, E. (1806). The History, Civil and Commercial, of the British Colonies in the West Indies (4 Vols.). Printed and sold by James Humphreys.

Cohen, J. J. (2017). Grey: A Zombie Ecology. In S. J. Lauro (Ed.), Zombie Theory (pp. 381-394). University of Minnesota Press. doi: 10.5749/j.ctt1pwt6zr.29

Davies, S. B. (2007). Raising the Dead: The Xhosa Cattle-Killing and the Mhlakaza-Goliat Delusion. Journal of Southern African Studies, 33(1), 19-41. doi: 10.1080/03057070601136517

Fehrle, J. (2016). "Zombies Don't Recognize Borders": Capitalism, Ecology, and Mobility in the Zombie Outbreak Narrative. Amerikastudien / American Studies, 61(4), 527-544.

Henson, S. L. A. (2002). Dead Bones Dancing: The Taki Onqoy, Archaism, and Crisis in Sixteenth Century Peru. East Tennessee State University.

Hillard, T. J. (2009). "Deep Into That Darkness Peering": An Essay on Gothic Nature. Interdisciplinary Studies in Literature and Environment, 16(4), 685-695. doi: 10.1093/isle/isp090

Kormann, C. (2021, October 12). The Mysterious Case of the COVID-19 Lab-Leak Theory. The New Yorker. https://www.newyorker.com/science/elements/the-mysterious-case-of-the-covid19-lab-leak-theory

Kramer, J. (2021, June 5). What you need to know about the COVID-19 lab-leak hypothesis. National Geographic. https://www.nationalgeographic.com/science/article/what-you-need-toknow-about-the-covid-19-lab-leak-hypothesis

La Barre, W. (1970). The Ghost Dance: Origins of Religion. Doubleday.

Lauro, S. J., \& Embry, K. (2008). A Zombie Manifesto: The Nonhuman Condition in the Era of Advanced Capitalism. Boundary 2, 35(1), 85-108. doi: 10.1215/01903659-2007-027

Lawton, G., \& Marshall, M. (2021). Did covid-19 come from a lab? New Scientist, 250(3337), 10-11. doi: 10.1016/S0262-4079(21)00938-6

Long, E. (1774). The History of Jamaica. Or, General survey of the antient and modern state of the island: With reflections on its situation settlements, inhabitants, climate, products, commerce, laws, and government. In three volumes. Illustrated with copper plates (Vol. 2). Printed for T. Lowndes, in Fleet-Street.

Longfellow, H. (1868). The New-England tragedies. Ticknor and Fields.

Marly, or, A Planter's Life in Jamaica. (1828). R. Griffin \& Co.

Matheson, R. (2007). I am legend (2. Tor ed). Tor.

Maxmen, A., \& Mallapaty, S. (2021). The COVID lab-leak hypothesis: What scientists do and don't know. Nature, 594(7863), 313-315. doi: 10.1038/d41586-021-01529-3

Mayne Reid. (1862). The maroon (3Vols.). Hurst and Blackett. 
Mcglotten, S., \& Vangundy, S. (2013). Zombie Porn 1.0: Or, Some Queer Things Zombie Sex Can Teach Us. Qui Parle, 21(2), 101-125. doi: 10.5250/quiparle.21.2.0101

Mintz, S. W. (1986). Sweetness and Power: The Place of Sugar in Modern History (Reprint edition). Penguin Books.

Moles, A. (2014). The Zombie Paradigm: Question Everything. AQ: Australian Quarterly, 85(3), 3-6. JSTOR.

Mooney, J. (1896). The Ghost-dance Religion and the Sioux Outbreak of 1890.

Morissette, J. J. (2013). Marxferatu: The Vampire Metaphor as a Tool for Teaching Marx's Critique of Capitalism. PS: Political Science and Politics, 46(3), 637-642.

Mukherjee, U. P. (2010). Postcolonial environments: Nature, culture and the contemporary Indian novel in English. Palgrave Macmillan/Arts \& Humanities Research Council.

Newbury, M. (2012). Fast Zombie/Slow Zombie: Food Writing, Horror Movies, and Agribusiness Apocalypse. American Literary History, 24(1), 87-114. JSTOR.

Newitz, A. (2006). Pretend We're Dead: Capitalist Monsters in American Pop Culture. Duke University Press. doi: 10.1215/9780822387855

Oloff, K. (2012). 'Greening' The Zombie: Caribbean Gothic, World-Ecology, and Socio-Ecological Degradation. Green Letters, 16(1), 31-45. doi: 10.1080/14688417.2012.10589098

Proyas, A. (2004). I, Robot [Action film]. 20th Century Fox.

Sanders, R. (2017). Ghost in the Shell [Science fiction action film]. Paramount Pictures.

Sanford, M. (1974). Revitalization Movements as Indicators of Completed Acculturation. Comparative Studies in Society and History, 16(4), 504-518. doi: 10.1017/S001041750000757X

Shaviro, S. (2002). Capitalist Monsters. Historical Materialism, 10(4), 281-290. doi: $10.1163 / 15692060260474486$

Shirō, M. (2017). The ghost in the shell. Glénat.

St. John, Spencer, S. (1884). Hayti: Or, The Black Republic. Smith, Elder, \& Company.

St. John, S. (1889). Hayti, or, the Black republic. Scribner \& Welford.

Wallace, A. F. C. (1956). Revitalization Movements. American Anthropologist, 58(2), 264-281. doi: 10.1525/aa.1956.58.2.02a00040

Walvin, J. (1996). Questioning Slavery (1st edition). Routledge.

Walvin, J. (2018). Sugar: The world corrupted: from slavery to obesity (First Pegasus Books hardcover edition). Pegasus Books.

Webb, J., \& Byrnand, S. (2017). Some Kind of Virus: In S. J. Lauro (Ed.), Zombie Theory (pp. 111-123). University of Minnesota Press. doi: 10.5749/j.ctt1pwt6zr.11

Быков, Д. $(2021,22)$. Новая газета. В. П-Ин Как Зеркало. https://novayagazeta.ru/articles/2021/11/19/pokolenie-p-in

Делёз, Ж., \& Гваттари, Ф. (2008). Анти-Эдип: Капитализм и шизофрения. У-Фактория.

Ленин, В. И. (1958). Полное собрание сочинений в 55 томах (Vol. 5).

Шторм, А. (2020, April 7). Коронавирус COVID-19: Случайность или биооружие? Pravda.Ru. https://www.pravda.ru/politics/1486840-biowar19/ 
Яшлавский, А. (2021, Мау 29). Китайскую лабораторию доказательно обвинили в создании коронавируса. Московский Комсомолеu. https://www.mk.ru/science/2021/05/29/kitayskuyulaboratoriyu-dokazatelno-obvinili-v-sozdanii-koronavirusa.html

\section{References}

Andersson, R.-H. (2008). The Lakota ghost dance of 1890. University of Nebraska Press.

Asimov, I. (2004). I, robot. Bantam Books.

Blouet, O. M. (2000). Bryan Edwards, F.R.S., 1743-1800. Notes and Records of the Royal Society of London, 54(2), 215-222.

Brown, T. L. (2008). Making Truth: Metaphor in Science (1st edition). University of Illinois Press.

Bryan, E. (1806). The History, Civil and Commercial, of the British Colonies in the West Indies (4Vols.). Printed and sold by James Humphreys.

Bykov, D. (2021, 22). Novaya Gazeta. V. P-Int. as a Mirror. https://novayagazeta.ru/articles/2021/11/19/pokolenie-p-in (In Russian)

Cohen, J. J. (2017). Grey: A Zombie Ecology. In S. J. Lauro (Ed.), Zombie Theory (pp. 381-394). University of Minnesota Press. doi: 10.5749/j.cttlpwt6zr.29

Davies, S. B. (2007). Raising the Dead: The Xhosa Cattle-Killing and the Mhlakaza-Goliat Delusion. Journal of Southern African Studies, 33(1), 19-41. doi: 10.1080/03057070601136517

Deleuze, J., \& Guattari, F. (2008). Anti-Oedipus: Capitalism and Schizophrenia. U-Factoria. (In Russian)

Fehrle, J. (2016). "Zombies Don't Recognize Borders": Capitalism, Ecology, and Mobility in the Zombie Outbreak Narrative. Amerikastudien / American Studies, 61(4), 527-544.

Henson, S. L. A. (2002). Dead Bones Dancing: The Taki Onqoy, Archaism, and Crisis in Sixteenth Century Peru. East Tennessee State University.

Hillard, T. J. (2009). "Deep Into That Darkness Peering": An Essay on Gothic Nature. Interdisciplinary Studies in Literature and Environment, 16(4), 685-695. https://doi.org/10.1093/isle/isp090

Kormann, C. (2021, October 12). The Mysterious Case of the COVID-19 Lab-Leak Theory. The New Yorker. https://www.newyorker.com/science/elements/the-mysterious-case-of-the-covid19-lab-leak-theory

Kramer, J. (2021, June 5). What you need to know about the COVID-19 lab-leak hypothesis. National Geographic. https://www.nationalgeographic.com/science/article/what-you-need-toknow-about-the-covid-19-lab-leak-hypothesis

La Barre, W. (1970). The Ghost Dance: Origins of Religion. Doubleday.

Lauro, S. J., \& Embry, K. (2008). A Zombie Manifesto: The Nonhuman Condition in the Era of Advanced Capitalism. Boundary 2, 35(1), 85-108. doi: 10.1215/01903659-2007-027

Lawton, G., \& Marshall, M. (2021). Did covid-19 come from a lab? New Scientist, 250(3337), 10-11. doi: 10.1016/S0262-4079(21)00938-6

Lenin, V. I. (1958). Complete Works in 55 Volumes (Vol. 5). (In Russian)

Long, E. (1774). The History of Jamaica. Or, General survey of the antient and modern state of the island:: With reflections on its situation settlements, inhabitants, climate, products, commerce, laws, and 
government. In three volumes. Illustrated with copper plates (Vol. 2). Printed for T. Lowndes, in Fleet-Street.

Longfellow, H. (1868). The New-England tragedies. Ticknor and Fields.

Marly, or, A Planter's Life in Jamaica. (1828). R. Griffin \& Co.

Matheson, R. (2007). I am legend (2. Tor ed). Tor.

Maxmen, A., \& Mallapaty, S. (2021). The COVID lab-leak hypothesis: What scientists do and don't know. Nature, 594(7863), 313-315. doi: 10.1038/d41586-021-01529-3

Mayne Reid. (1862). The maroon (3Vols). Hurst and Blackett.

Mcglotten, S., \& Vangundy, S. (2013). Zombie Porn 1.0: Or, Some Queer Things Zombie Sex Can Teach Us. Qui Parle, 21(2), 101-125. doi: 10.5250/quiparle.21.2.0101

Mintz, S. W. (1986). Sweetness and Power: The Place of Sugar in Modern History (Reprint edition). Penguin Books.

Moles, A. (2014). The Zombie Paradigm: Question Everything. AQ: Australian Quarterly, 85(3), 3-6. JSTOR.

Mooney, J. (1896). The Ghost-dance Religion and the Sioux Outbreak of 1890.

Morissette, J. J. (2013). Marxferatu: The Vampire Metaphor as a Tool for Teaching Marx's Critique of Capitalism. PS: Political Science and Politics, 46(3), 637-642.

Mukherjee, U. P. (2010). Postcolonial environments: Nature, culture and the contemporary Indian novel in English. Palgrave Macmillan/Arts \& Humanities Research Council. http://site.ebrary.com/id/10425011

Newbury, M. (2012). Fast Zombie/Slow Zombie: Food Writing, Horror Movies, and Agribusiness Apocalypse. American Literary History, 24(1), 87-114. JSTOR.

Newitz, A. (2006). Pretend We're Dead: Capitalist Monsters in American Pop Culture. Duke University Press. doi: 10.1215/9780822387855

Oloff, K. (2012). ‘Greening' The Zombie: Caribbean Gothic, World-Ecology, and Socio-Ecological Degradation. Green Letters, 16(1), 31-45. doi: 10.1080/14688417.2012.10589098

Proyas, A. (2004). I, Robot [Action film]. 20th Century Fox.

Sanders, R. (2017). Ghost in the Shell [Science fiction action film]. Paramount Pictures.

Sanford, M. (1974). Revitalization Movements as Indicators of Completed Acculturation. Comparative Studies in Society and History, 16(4), 504-518. doi: 10.1017/S001041750000757X

Shaviro, S. (2002). Capitalist Monsters. Historical Materialism, 10(4), 281-290. doi: 10.1163/15692060260474486

Shirō, M. (2017). The ghost in the shell. Glénat.

Shtorm, A. (2020, April 7). Coronavirus COVID-19: Accident or bioweapon? Pravda.Ru. https://www.pravda.ru/politics/1486840-biowar19/In Russian)

St. John, Spencer, S. (1884). Hayti: Or, The Black Republic. Smith, Elder, \& Company.

St. John, S. (1889). Hayti, or, the Black republic. Scribner \& Welford.

Wallace, A. F. C. (1956). Revitalization Movements. American Anthropologist, 58(2), 264-281. doi: 10.1525/aa.1956.58.2.02a00040 
Walvin, J. (1996). Questioning Slavery (1st edition). Routledge.

Walvin, J. (2018). Sugar: The world corrupted: from slavery to obesity (First Pegasus Books hardcover edition). Pegasus Books.

Webb, J., \& Byrnand, S. (2017). Some Kind of Virus: In S. J. Lauro (Ed.), Zombie Theory (pp. 111-123). University of Minnesota Press. doi: 10.5749/j.ctt1pwt6zr.11

Yashlavsky, A. (2021, May 29). Chinese laboratory incriminated for creating coronavirus Moskovsky Komsomolets. https://www.mk.ru/science/2021/05/29/kitayskuyu-laboratoriyudokazatelno-obvinili-v-sozdanii-koronavirusa.html (In Russian) 